\title{
The Value of Pancasila on the Islamic Education Institution (Discourse Study of the Al-Imamah Book at SMA Al-Islam 1 Surakarta)
}

\author{
Galih Pranata \\ SMA AI- Islam 1 Surakarta, Kota Surakarta, Indonesia \\ galih.pranata@gmail.com
}

\section{Article History}

accepted 09/04/2021

approved 10/04/2021

published 20/04/2021

\begin{abstract}
Pancasila has become the ideology of the Indonesian nation, including the Islamic Foundation which is often juxtaposed with a non-Pancasila stigma that demands a caliphate state and abandons the values of Pancasila. Islamic foundations have always been a sentiment in Indonesian society today, so it is necessary to further ascertain the teachings conveyed by the Islamic Foundation, more specifically from the perspective of education. This study aims to see the existence of Pancasila in the social interactions of the Islamic Education Foundation, especially in SMA Al-Islam 1 Surakarta. The method in this study uses a qualitative paradigm through an interview approach and participatory observation. The results of this study indicate that there is a special study for teachers and employees at SMA Al-Islam 1 Surakarta using the book Al-Imamah by Kiyai Haji Imam Ghazali. This book is a summary of K. H Imam Ghazali's intellectual activities in the journey and history of struggle to build Al-Islam college as outlined through his writings and analysis of the holy verses of the Koran and Hadith as the founding principles of the Al-Islam Foundation itself. There is an implicit emphasis on the values of Pancasila contained in the book of Al-Imamah and it is conveyed periodically with a frequency of once a week. This study is expected to provide provisions and instill the values of religiosity and personality in acting and behaving.
\end{abstract}

Keywords : Yayasan Islam, Pancasila, Al-Islam, Imamah, SMA Al-Islam 1 Surakarta

\begin{abstract}
Abstrak
Pancasila menjadi ideologi bangsa Indonesia, tidak terkecuali bagi Yayasan Islam yang kerap disandingkan dengan stigma non-Pancasilais yang menuntut negara khilafah dan meninggalkan nilai-nilai pada Pancasila. Yayasan Islam selalu menjadi sentimen di masyarakat Indonesia saat ini, sehingga perlu dipastikan lebih jauh lagi tentang ajaran yang disampaikan Yayasan Islam, lebih khusus dalam perspektif Pendidikan. Penelitian ini bertujuan melihat keberadaan Pancasila dalam interaksi sosial Yayasan Pendidikan Islam, khususnya di SMA AIIslam 1 Surakarta. Metode dalam pengkajian ini menggunakan paradigma Kualitatif melalui pendekatan wawancara dan observasi partisipatif. Hasil penelitian ini menunjukan bahwa terdapat kajian khusus bagi para Guru dan Karyawan di SMA Al-Islam 1 Surakarta menggunakan kitab Al-Imamah karangan Kiyai Haji Imam Ghazali. Kitab ini merupakan ringkasan aktivitas intelektualisme K. H Imam Ghazali dalam perjalanan dan perjuangan sejarah membangun perguruan Al-Islam yang dituangkan melalui tulisan dan telaahnya pada ayat suci Al-Qur'an dan Hadits sebagai prinsip pendirian Yayasan Al-Islam itu sendiri. Terdapat secara implisit penekanan nilai-nilai Pancasila yang terkandung dalam kitab Al-Imamah dan disampaikan secara berkala dengan frekuensi satu kali dalam seminggu. Kajian ini diharapkan menjadi bekal dan penanaman nilai religiusitas dan kepribadian dalam bertindak dan berperilaku.
\end{abstract}

Kata Kunci : Yayasan Islam, Pancasila, Al-Islam, Imamah, SMA AI-Islam 1 Surakarta

Social, Humanities, and Education Studies (SHEs): Conference Series https://jurnal.uns.ac.id/shes

p-ISSN 2620-9284

e-ISSN 2620-9292

This work is licensed under a Creative Commons Attribution-ShareAlike 4.0 International License. 


\section{PENDAHULUAN}

Islam sejatinya menjadi agama pembawa kedamaian bagi seluruh alam atau rahmatan lil 'alamiin (Rasyid, 2016). Konteks dunia kontemporer telah menggeser wajah Islam kea rah sebaliknya, sebagai pembawa teror dan menjadi keresahan bagi kehidupan berbangsa dan bernegara (Rabasa, 2003). Stigma ini tentunya tidak terjadi hanya di lingkup Indonesia melainkan di Asia Tenggara, bahkan dunia. Stigma negative seakan telah melekat pada setiap organisasi kelembagaan Islam, tak terkecuali Yayasan Islam yang tersebar hampir di seluruh pelosok Negeri. Beberapa yayasan Islam dicurigai dan diduga sebagai sarang radikalisme (Redjosari, 2020). Hal ini menjadi kenyataan pahit sekaligus pukulan bagi dunia Islam. konsep rahmatan lil 'alamiin yang menjadi prinsip bagi sekalian umat telah bergeser maknanya menjadi yang sebaliknya. Pancasila menjadi pertanyaan besar dalam mengusung persatuan dan kesatuan dimana aksi terorisme selalu muncul dengan dalih perbedaan cara pandang, utamanya cara beragama.

Pandangan Jihad terhadap kaum kafir masih melekat dan menjadi stigma para peneror yang serta merta berdampak pada keresahan publik. Pancasila seharusnya menempatkan kemanusiaan diatas segalanya, dengan rasa persatuan dan toleransi, kearifan dan keadilan sebagai masyarakat benegara dan beragama (Simanjuntak \& Benuf, 2020). Salah satu Yayasan Islam besar di Surkaarta adalah Yayasan Perguruan Al-Islam. dalam konteks kajian ini, peneliti berupaya mengeksplorasi kajian internal bagi para guru dan karyawan sebagai upaya membuka pandangan baru bagi dunia luar dalam memahami Islam dan interaksi didalamnya. Salah satu kajian internalnya adalah Kajian Kitab Al-Imamah, karya pendiri Perguruan Al-Islam Surakarta, KH. Imam Ghazali ibn Hasan Ustadz. Kitab Imamah ditulis sekitar pertengahan 1968 hasil buah gagasan KH. Imam Ghazali dalam perjalanannya merintis pendidikan Islam sejak era pemerintahan Hindia-Belanda berkuasa di Surakarta hingga kemelut perkembangan awal kemerdekaan (Abdullah, 2016).

Al-Imamah disadur dari landasan ayat-ayat suci Al-Qur'an sebagai sumber utama penulisan dengan perkuatan hadits sebagai penafsirannya. $\mathrm{KH}$. Imam Ghazali berupaya menuangkan gagasannya tentang kepemimpinan di dalam Kitab Imamah sebagai pondasi keberlangsungan kehidupan bangsa dan Negara dalam perspektif Islam. Kitab Imamah berbicara banyak tentang kepemimpinan dan kebangsaan sehingga perlu adanya kajian yang membahas mengenai relevansinya pada ideologi dasar Negara, Pancasila. Maka dari itu, penelitian ini berupaya untuk melihat keberadaan Pancasila dalam kajian Al-Imamah yang menjadi salah satu identitas kajian dari Yayasan Perguruan AI-Islam, utamanya di SMA Al-Islam 1 Surakarta.

Teori

Konsep Pancasila merupakan pandangan hidup dan suatu konsesus sebagai warga negara yang berkomitmen untuk bersatu dalam ideologi untuk mencapai tujuan bersama (Kaderi, 2002). Pancasila menjadi elemen penting yang seharusnya menjadi acuan dalam menerapkan kebijakan kenegaraan agar selaras dengan tujuan Pancasila (Azikin, 2018). Begitu juga penerapan pancasila dalam elemen kemasyarakatan, harus masuk dalam kehidupan sehari-hari masyarakat Indonesia. Salah satu halnya adalah penerapan Pancasila dalam jenjang pendidikan. Refleksi Pancasila dalam dunia pendidikan juga perlu ditanamkan melalui pembudayaan atau pembiasaan. Richard C. Martin (1985) sebagai peneliti muslim pada proses transmisi nilai mengemukakan bahwa transmisi Nilai dalam Pendekatan Religiusitas dapat dilakukan melalui pembudayaan atau habituasi individu dalam pola-pola agama yang berlaku. Salah satu upaya yang dilakukan adalah melalui refleksi nilai yang disampaikan pada kajian-kajian islami sehingga dapat berpengaruh bagi pola kehidupan sehari-hari (Sufirmansyah \& Badriyah, 2020). 


\section{METODE}

Metode dalam pengkajian ini menggunakan paradigma Kualitatif melalui pendekatan wawancara dan observasi partisipatif. Wawancara merupakan alat pengambilan data yang digunakan dalam paradigma kualitatif, dalam mengukur dan mencari perihal "bagaimana" dan "mengapa" dalam sebuah penelitian (Kvale, 1994). Kualitatif mendasarkan pada interview-investigate sebagai equipment dalam mengumpulkan data (Matarazzo \& Wiens, 2009). Selain wawancara sebagai penguatan data, dilakukan juga observasi. Salah satu teknik yang digunakan dalam observasi adalah observasi partisipatif. Teknik ini menempatkan peneliti sebagai pelaku yang berinteraksi dengan objek penelitian, seperti halnya dalam mengambil data secara langsung terhadap objek (Johnson, 1975).

\section{HASIL DAN PEMBAHASAN}

$\mathrm{KH}$. Imam Ghazali merupakan pendiri dari Perguruan Al-Islam dan salah satu pelopor pengembangan pendidikan Islam di Era Hindia-Belanda sejak 1928. Beliau juga telah menempa diri dalam perjalanan intelektualisme islam yang panjang dan terjal, melihat birokrasi pendidikan Islam masih sangat dibatasi era Pemerintahan Hindia-Belanda. Riwayat pendidikan yang ditempuh oleh KH. Imam Ghazali ditempuh selama 4 tahun selama menjadi santri di Pondok Jamsaren yang dirintis oleh $\mathrm{KH}$. Idris dan didanai langsung oleh Pakubuwana $X$. Dari hasil perjalanan intelektualnya, beliau telah mampu menciptakan berbagai karya seperti Kitab Al-Imamah, At-Tijan, Al-Adabu wa al-Akhlaq an- Nabawiyyah, Al-Islam wa al-Muslimin, Al-Qur'an wa Sunnah Sayyid al-Anam, dan masih banyak lagi karya lainnya (Agustien, 2020). Upaya melakukan transmisi melalui pengkajian yang mendalam dalam menelaah Al-Qur'an dan AsSunnah dilakukan untuk menciptakan perspektif yang baru yang menjadi penengah diantara krisis golongan dalam tubuh Islam di Nusantara kala itu. Salah satu kitab yang masih eksis disampaikan pada kajian-kajian di Yayasan Perguruan Al-Islam adalah Kajian Al-Imamah.

Kajian Al-Imamah yang merupakan salah satu dari sekian banyak karya $\mathrm{KH}$. Imam Ghazali dalam mengembangkan perspektif dan keilmuannya tentang Islam. Sampai saat ini belum jelas tahun berapa kitab Imamah ditulis, namun kuat dugaan penulis melalui penelaahan sumber, Kitab Al-Imamah selesai ditulis oleh $\mathrm{KH}$ Imam Ghazali pada 19 Juni 1968 atau 23 Rabi'ul Awal 1388 H. Kajian Imamah menjadi salah satu medium yang digunakan oleh para penerus Perguruan Al-Islam dalam melestarikan intelektualisme keislaman dari KH. Imam Ghazali. Kajian Imamah menyandarkan pokok bahasannya pada tafsirul qur'an dan riwayat-riwayat dalam Hadits shahih dengan konsep tematik, atau pengkajian spesifik berdasarkan tema (Abdullah, 2016). Sampai hari ini, di tahun 2021 di masa pandemi, kajian Al-Imamah masih tetap berlangsung secara blended, melalui online dan offline sebagai upaya penyampaian nilai-nilai yang utama dalam melestarikan gagasan keislaman dan perspektif khas Al-Islam.

\section{A. Pancasila dalam Perpspektif Kajian Al-Imamah}

Pancasila sebagai ideologi negara telah menjadi tujuan dari terciptanya masyarakat yang baik bersikap dalam kehidupan berbangsa dan bernegara. Pancasila sebagai Weltanschaaung (Pandangan Materialistik) dalam kehidupan berbangsa dan bernegara, bermuara pada penciptaan individu dan masyarakat bangsa dalam menjunjung nilai-nilai Ketuhanan yang berbudaya dan beradab dalam persatuan dan kesatuan (Arif, 2016). Agama yang menjadi elemen penting dalam kehidupan bernegara masyarakat Indonesia tentunya tidak terlepas dari Weltanschaaung Pancasila.

Al-Imamah memiliki relevansi yang erat pada nilai-nilai Pancasila. Di dalam bagian dan sub-bab nya mengandung ayat-ayat yang memiliki kajian spesifik mengenai kepemimpinan dan bangsa, termasuk di dalamnya adalah Pancasila. 


\section{Sila Pertama: Ketuhanan yang masa Esa}

Pada kitab Imamah di BAB I \& II dengan tema Al-Qur'an dan Risalah Rasul banyak membahas mengenai Keesaan Tuhan, lebih khusus penghambaan kepada Allah SWT dalam ajaran islam. seperti halnya pada Qs. Al-lkhlash ayat 1-4 yang merepresentasi perwujudan Keesaan Allah SWT. Dikatakan bahwa dalam Tafsir Ibnu Katsir, pada ayat pertama dikisahkan tentang seruan Allah kepada sekalian makhluk untuk menyebut Keesaaan Allah dari sekian banyak perantara lain yang disembah. Begitu pula pada ayat-ayat selanjutnya yang menegaskan bahwa Allah adalah tempat bergantung sekalian makhluk dan ciptaannya. Dari perspektif ini, jelas bahwa kutipan Al-Imamah merujuk pada nilai dalam Sila pertama. Pada kutipan lain dalam Imamah juga disebutkan mengenai hadits riwayat Ibnu Mas'ud, tentang Ulama Yahudi yang berbicara keesaan Allah melalui Taurat yang membuat Rasulullah tertawa bahagia. Dari sini dapat ditarik kesimpulan bahwa seorang Ulama Yahudi mengakui keesaan Allah melalui Taurat yang la baca dan pelajari, bahwa segala hal yang dihamparkan di langit dan bumi hanya dihamparkan melalui satu telunjuk jari, menandakan Keagungan dan Keesaan Allah SWT.

Pada konteks Pancasila, masyarakat beragama (utamanya Agama Samawi) merujuk pada prinsip Monetheism atau Kepercayaan Tunggal, sehingga dalam kajian ini dianggap relevan pada prinsip Ketuhanan yang Maha Esa. Penyandaran kepada Kitabullah sebagaimana paradigma penulisan Kitab AlImamah menjadi syiar dalam menyampaikan kebenaran sebagai warga Negara yang beragama. Sebagaimana tafsir Al-Wajiz dalam Qs. At-Thariq ayat ke-13 dan 14 yang menegaskan bahwa, Al-Qur'an menjadi petunjuk umat Islam, sebagai petunjuk manusia dalam beragama, yang memberikan pemahaman manusia tentang yang hak dan yang bathil.

\section{Sila Kedua: Kemanusiaan Yang Adil Dan Beradab}

Imamah dalam konteks sila kedua merujuk pada bagian ke-III dengan tema kajian Berpegang teguh pada Kitabullah. Pada Qs. Qs. Ali Imran ayat 110, menjelaskan bahwa islam dilahirkan untuk menjadi rahmatan lil'alamin, begitu pula dalam hal menegakkan ammar ma'ruf nahi munkar sebagai ikhtiar dalam membangun manusia yang beradab yang berlandaskan Ketuhanan. Adapula dari Qs. Al-Ma'idah ayat 8 yang menjelaskan tentang seruan Allah agar manusia memiliki sifat adil sebagai bukti ketaqwaan kepada sang Khaliq. Redaksi ayat:

\section{"....Berlaku adillah, karena adil itu lebih dekat kepada}

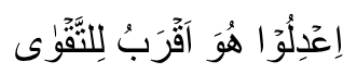

\section{takwa.."}

Kutipan dari Qs. Al-Ma'idah ayat 8. menjelaskan bahwa sudah menjadi tanggungjawab kita sebagai manusia (khalifah fil ardh) berlaku adil kepada semua. Keutamaan berlaku adil adalah akan dicintai oleh Allah SWT, seperti firman-Nya,

"Dan hendaklah kamu berlaku adil. Sesungguhnya Allah mencintai orang-orang yang berlaku adil." (QS. Al-Hujurat: 9).

Representasi dari ayat tersebut menunjukkan jika Allah SWT sudah mencintai seorang hamba $\left(a b d^{\prime}\right)$, maka semua makhluk juga akan mencintainya, yang ada di langit dan juga di bumi. Nabi SAW bersabda, "Jika Allah mencintai seseorang, Dia menyeru Jibril, "Sesungguhnya Allah mencintai si fulan, cintailah ia". Jibril lalu mencintainya. Lantas Jibril menyeru penduduk langit, "Sesungguhnya Allah mencintai si fulan, cintailah ia." Penduduk langit pun mencintainya. Akhirnya, cinta itu diteruskan bagi penduduk di bumi" (HR. Bukhari). Dari serangkaian konteks adil dalam pengamalan Sila kedua, maka imbasnya adalah timbulnya rasa saling cinta dan mengasihi sesame, baik secara vertikal/dengan Allah SWT 
(habluminallah) maupun secara horizontal/dengan sesama makhluk (habluminannaas).

\section{Sila Ketiga: Persatuan Indonesia}

Selain perilaku adil dan beradab dalam Sila Kedua untuk menciptakan keselarasan dan hubungan baik bagi sesama, dalam Sila Ketiga juga dijelaskan mengenai persatuan Indonesia. Dalam konteks persatuan Indonesia, sejatinya didasari dari rasa saling menghargai dan keberterimaan terhadap sesama (Hermawati, et al., 2016). Pada proses menjadil hubungan yang baik sesama manusia atau dikenal dengan konsep habluminannas sejatinya juga terdiri dari rasa saling toleransi terhadap keberagaman, seperti yang tertulis dalam Qs. AlHujurat ayat ke-13.

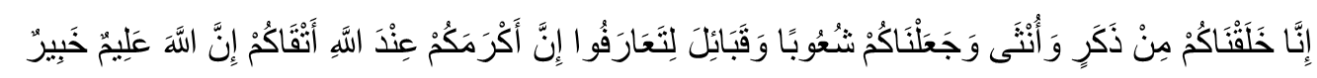

“...sesungguhnya Kami menciptakan kamu dari seorang laki-laki dan seorang perempuan dan menjadikan kamu berbangsa-bangsa dan bersuku-suku supaya kamu saling kenal-mengenal. Sesungguhnya orang yang paling mulia di antara kamu di sisi Allah ialah orang yang paling bertakwa di antara kamu. Sesungguhnya Allah Maha Mengetahui lagi Maha Mengenal' (Qs. Al-Hujurat: 13)

Keberagaman antar umat beragama dan warga Negara yang berbudaya menjadi identitas Indonesia sebagai bangsa yang majemuk. Pada Sila ketiga ini, diusung gagasan mengenai persatuan diantara sekalian elemen untuk mencapai tujuan bersama. Dalam konteks Qs. Al-Hujurat ayat ke-13, Allah SWT telah berfirman dan menegaskan bahwa perbedaan diantara sesama manusia, baik keberagaman suku dan bangsa bertujuan untuk saling menjalin hubungan baik dan erat serta menjalin persaudaran dalam satu ikatan (Pranata, 2016). Dalam Tafsir Ibnu Katsir juga disebutkan lebih rinci mengenai makna "saling mengenal" dalam Qs. Hujurat ayat ke-13, bersandar pada hadits Abu Hurairah r.a., bahwasannya rasa saling mengenal mempererat silaturahmi (hubungan kekeluargaan), karena sesungguhnya silaturahmi itu menanamkan rasa cinta kepada rasa kekeluargaan, memperbanyak harta, dan memperpanjang usia.

Al-Qur'an yang disampaikan oleh Muhammad SAW memberi pesan nonMisoginisme (tanpa kebencian) dan saling menghargai keberagaman (universalitas) dengan saling memegang syari'at islam Kisah Umar R.A yang memilih shalat di luar gereja (pintu gereja) karena kesulitan mencari masjid di wilayah Jerrusalem. Bukannya menjauh dan menghindari uskup yang berbeda agama, apalagi bersikap radikal. Islam mengajarkan rasa saling mencintai sesama makhluk dengan mengedepankan rasa cinta damai sesama manusia. Hal tersebut menunjukkan bahwa pengkajian dalam kitab Imamah juga menjelaskan konsep tentang ukhuwah (persaudaran).

4. Sila keempat: Kerakyatan yang Dipimpin oleh Hikmat Kebijaksanaan dalam Permusyawaratan/ Perwakilan

Demokrasi yang telah menjadi prinsip Negara merupakan bagian dari permusyawaratan dalam merumuskan kebijakan-kebijakan kenegaraan. Qs. Asyu'ara' ayat ke-38, menjelaskan konsep tentang musyawarah sebagai proses tawakkal kepada Allah SWT dalam menyelesaikan urusan kemanusiaan (umat).

"...sedangkan urusan mereka (diputuskan) dengan

$$
\text { وَأَْْرُ هُمْ شُورَى بَيْنَهُْْ }
$$
musyawarah antara mereka." (Asy-Syura: 38)

Tafsir Ibnu Katsir menjelaskan bahwa mereka (ummat Muhammad SAW), tidak pernah memutuskan sesuatu urusan melainkan terlebih dahulu mereka 
musyawarahkannya di antara sesamanya agar masing-masing dari mereka mengemukakan pendapatnya. Seperti dalam menghadapi urusan perang dan lain sebagainya yang penting. Hal yang sama telah dilakukan oleh Khalifah Umar ibnul Khattab r.a. saat menjelang ajalnya karena tertusuk, ia menjadikan urusan kekhalifahan sesudahnya agar dimusyawarahkan di antara sesama mereka untuk memilih salah seorang dari enam orang berikut, yaitu Usman, Ali, Talhah, AzZubair, Sa'd, dan Abdur Rahman ibnu Auf (Mulyana, 2017).

Konteks tersebut juga relevan dengan musyawarah kenegaraan dan kebangsaan. Selain itu, terdapat juga di dalam Kitabul Imamah tentang unsur adab-adab mudzakarrah yang salah satunya adalah menghargai pendapat orang lain. Dalil ini menegaskan keberterimaan dalam bermusyawarah sebagai bentuk penghargaan terhadap orang lain, respresentasi kesamaan hak dihadapan Allah dan hukum bernegara. Adab-adab dalam Mudzakarrah adalah sikap yang diambil di dalam diskusi. Maksud dan tujuan mudzakarah ini adalah untuk meningkatkan keimanan pada diri sendiri dan islah diri sendiri agar tumbuh dalam diri manusia suatu gairah terhadap amalan (Ulum, 2010). Adab-adab dalam mudzakarrah sangat diperlukan dalam konteks menumbuhkan keimanan dan kedewasaan diri dalam suatu syura atau musyawarah. Apabila satu gagasan atau usulan tidak diterima, mudzakarrah sebagai medium untuk mendorong rasa keberterimaan.

\section{Sila Kelima: Keadilan Sosial Bagi Seluruh Rakyat Indonesia}

Pada bagian ini, Qs. Shod ayat ke-26 menjadi pengingat apabila kelak menjadi pemimpin yang tidak hanya amanah, tapi juga bajik dan adil. Tidak menuruti hawa nafsu sebagai penguasa, sebagaimana Daud yang diutus sebagai khalifah yang harus berlaku adil dan tidak menuruti hawa nafsu. Prinsipnya pada ayat tersebut, maka para pemimpin yang menuruti hawa nafsu hidupnya telah sesat dan akan mendapat hukuman Allah SWT karena melupakan hari perhitungan.

"Hai

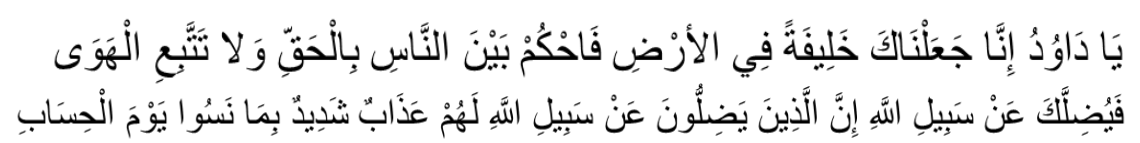

Daud! sesungguhnya Kami menjadikan kamu khalifah (penguasa) di muka bumi, maka berilah keputusan (perkara) di antara manusia dengan adil dan janganlah kamu mengikuti hawa nafsu, karena ia akan menyesatkan kamu dari jalan Allah. Sesungguhnya orang-orang yang sesat dari jalan Allah akan mendapat azab yang berat, karena mereka melupakan hari perhitungan" (Qs. Shad: 26)

Hak individu juga sebagai warga negara untuk mendapatkan keadilan, sebagaimana ketaatan kepada pemimpin yang bertakwa dan memberi nasihat kepada pemimpin yang Ialim dan dzhalim. Dalam kitabnya, KH. Imam Ghazali bin Hasan Ustadz (2015) berpesan untuk menyampaikan nasihat dari Allah SWT sebagaimana yang dilakukan para waliyullah (Nabi \& Rasul) karena sejatinya agama adalah sebaik-baiknya nasihat, dan sebaik-baiknya pemimpin adalah yang mau mendengarkan nasihat umatnya.

\section{SIMPULAN}

SMA Al-Islam 1 Surakarta merupakan bagian dari sekolah yang dinaungi Yayasan Al-Islam Surakarta sehingga juga memiliki karakteristik pengkajian Kitab AlImamah. Dalam kitab Al-Imamah terdapat nilai-nilai Pancasila yang tersirat dan tersurat. Diantaranya pada Sila Pertama tentang Ketuhanan YME yang berlandas pada Qs. Al-lkhlash ayat 1-4 yang menjelaskan Keesaan Allah SWT. Dalam beberapa bagian juga membahas mengenai Sila Kedua seperti halnya penanaman perilaku adil dan beradab dalam Qs. Al-Ma'idah ayat 8. Sila Ketiga juga termaktub pada Kitab Imamah dalam konteks Qs. Hujurat ayat 13 mengenai toleransi dan keberterimaan 
pada kemajemukan. Dalam Sila Keempat dijelaskan juga bahwa dalam Imamah terdapat adab-adab dalam musyawarah untuk beriman dan bersikap dewasa dalam perihal syura dan demokrasi. Sila Kelima digambarkan melalui hak memperoleh keadilan dan anjuran untuk menasihati pemimpin dengan firman Allah SWT sebagai bentuk keimanan.

\section{DAFTAR PUSTAKA}

Ghazali, Imam. (2015). Kitab Al-Imamah (Cetakan Kedua). Surakarta: Maktabah AlMa'muriyah

Hermawati, R., Paskarina, C. \& Runiawati, N., (2016). Toleransi Antar Umat Beragama di Kota Bandung. UMBARA : Indonesian Journal of Anthropology. 1(2), pp.105125

Johnson, John M., (1975). Doing Field Research. New York: Free Press

Kaderi, Alwi. (2015). Pendidikan Pancasila Untuk Perguruan Tinggi. Banjarmasin: Antasari Press

Kvale, Steinar. (1994). InterViews: An introduction to qualitative research interviewing. New York: Sage Publications, Inc.

Martin, Richard C., (1982). Islam, A Cultural Perspective. New Jersey: Englewood Cliffs, N.J. Prentice-Hall.

Matarazoo, Joseph D., \& Wiens, Arthur N., (2009). The Interview: Research on Its Anatomy and Structure. New Brunswick: Aldine Transaction

Mulyana, Ade. (2017). Pembentukan Majlis Syura oleh Umar bin Khatthab untuk Menyelenggarakan Pemilihan Khalifah. Al-Ahkam, 13(1), pp. 21-46

Pranata, Galih. (2016). Implementasi Nilai - Nilai Kebangsaan Dalam Al-Qur'an Pada Pembelajaran Sejarah (Studi Kasus Pembelajaran Sejarah di Kelas XI SMA MTA Surakarta Tahun Ajaran 2015/2016). Skripsi. Universitas Sebelas Maret Surakarta

Rabasa, Angel M., (2003). Political Islam in Southeast Asia: Moderates, Radical and Terrorists. New York: Routledge Taylor \& Francis Group

Rasyid, Muhammad Makmun. (2016). Islam Rahmatan lil Alamin Perspektif KH. Hasyim Muzadi. Epistemé: Jurnal Pengembangan IImu Keislaman, 11(1), pp.93-116.

Redjosari, Muliono Slamet. (2020). Islam dan Stigma Radikalisme. Surabaya: Airlangga University Press

Simanjuntak, Supriardoyo \& Benuf, Kornelius. (2020). Relevansi Nilai Ketuhanan dan Nilai Kemanusiaan dalam Pemberantasan Tindak Pidana Korupsi. DIVERSI : Jurnal Hukum. 6(1), pp. 22-46

Sufirmansyah \& Badriyah, Lailatul. (2020). Telaah Kritis Eksistensi Pesantren sebagai Refleksi Pendidikan Islam Holistik dalam Membentuk Generasi Muslim Berkarakter. JolEM: Journal of Islamic Education Management. 1(1), pp.1-21

Ulum, Muhammad Miftakhul. (2010). Dakwah Jamaah Tabligh di Pondok Pesantren Al Fatah Temboro Magetan: analisis Framing. Undergraduate thesis, IAIN Sunan Ampel Surabaya. 